Volume 4, Issue 1 Janaury-March 2019, Pages: 277, DOI: http://dx.doi.org/10.19082/ah277

\title{
ISOLATION AND IN SILICO CHARACTERIZATION OF A LEISHMANICIDAL DISINTEGRIN FROM CERASTES CERASTES VENOM
}

\author{
Dihia Allane ${ }^{1}$, Habiba Oussedik-Oumehdi ${ }^{1}$, Zoubir Harrat ${ }^{2}$, Sylvie Michelland ${ }^{3}$, Michel Seve ${ }^{3}$, Fatima Laraba- \\ Djebari $^{1}$
}

flaraba@hotmail.com,flaraba@usthb.dz,habibaoussedik_27@hotmail.com,houssedik@usthb.dz

1: USTHB, Faculté des Sciences Biologiques, Laboratoire de Biologie Cellulaire et Moléculaire, BP 32, El -Alia Bab Ezzouar, 16111, Alger, Algérie

2: Institut Pasteur d'Algérie, Service d'Eco-Epidémiologie Parasitaire, Dely Ibrahim 16047 Alger, Algérie

3: CHU Grenoble Alpes, Institut de Biologie et de Pathologie, PrometheeProteomic Platform, Grenoble, France

\section{TYPE OF ARTICLE: CONFERENCE ABSTRACT}

\begin{abstract}
Background: Leishmaniasis represents a serious public health problem in Algeria. The parasite, in the promastigote form, upon transfer by the infected vector to the vertebrate host, invades mononuclear macrophages and causes substantial human morbidity and mortality. Investigating new antimicrobial and antiparasitic components from Viperidae venoms represents an alternative therapeutic strategy for leishmaniasis treatment.

Objective: In the present study, we report the characterization of a disintegrin, isolated from Cerastes cerastes venom, exhibiting antiparasitic activity on Leishmania infantum promastigotes.

Methods: The active biomolecule, referred to as Disintegrin_Cc, was isolated by RP-HPLC chromatography. The in vitro antiparasitic activity of this molecule was evaluated on Leishmania infantum promastigotes. The isolated disintegrin was analyzed by SDS-PAGE for homogeneity and molecular weight determination and then subjected to MALDI-TOF MS/MS analysis. A 3D structure was predicted in silico using SWISS-Model.

Results: Isolated Disintegrin_Cc induced deep morphological alterations on the parasites and a strong antileishmanial activity estimated to $84.75 \%$ of mortality. SDS-PAGE analysis indicated that this disintegrin was homogenous. This dimeric disintegrin of 14,193.97 Da contains an RGD domain and four intramolecular disulfide bridges. This biomolecule presents a high percentage of identity with other related types of snake disintegrin. Predicted 3D structure indicated that this peptide shares partial homology with well-known active antimicrobial peptides.
\end{abstract}

Conclusion: This study demonstrated the leishmanicidal activity of Disintegrin_Cc. This molecule may be useful to design a new therapy against leishmaniasis.

KEYWORDS: Cerastes cerastes, Disintegrin, Leishmania, Venom

\footnotetext{
Abstracts of Third International Conference on Health Sciences and Medical Technologies, October 2018, Tlemcen, Algeria (ICHSMT-18)

(C) 2019 The Authors. This is an open access article under the terms of the Creative Commons Attribution-NonCommercialNoDerivs License, which permits use and distribution in any medium, provided the original work is properly cited, the use is non-commercial and no modifications or adaptations are made.
} 